\title{
BMJ Open Temporal trends and geographical disparities in comprehensive stroke centre capabilities in Japan from 2010 to 2018
}

\author{
Ai Kurogi (D) , ${ }^{1}$ Ataru Nishimura, ${ }^{1}$ Kunihiro Nishimura, ${ }^{2}$ Akiko Kada, ${ }^{3}$ \\ Daisuke Onozuka (D) , ${ }^{4}$ Akihito Hagihara, ${ }^{4}$ Kuniaki Ogasawara, ${ }^{5}$ Yoshiaki Shiokawa, ${ }^{6}$ \\ Takanari Kitazono, ${ }^{7}$ Koichi Arimura, ${ }^{1}$ Koji lihara, ${ }^{1}$ J-ASPECT Study Collaborators
}

To cite: Kurogi $A$,

Nishimura A, Nishimura $K$, et al. Temporal trends and geographical disparities in comprehensive stroke centre capabilities in Japan from 2010 to 2018. BMJ Open 2020;10:e033055. doi:10.1136/ bmjopen-2019-033055

- Prepublication history and additional material for this paper are available online. To view these files, please visit the journal online (http://dx.doi. org/10.1136/bmjopen-2019033055).

Received 22 July 2019

Revised 07 May 2020

Accepted 10 June 2020
Check for updates

(C) Author(s) (or their employer(s)) 2020. Re-use permitted under CC BY-NC. No commercial re-use. See rights and permissions. Published by BMJ.

For numbered affiliations see end of article.

Correspondence to

Dr Koji lihara;

kiihara@ns.med.kyushu-u.ac.jp

\section{ABSTRACT}

Objectives Comprehensive stroke centre (CSC) capabilities are associated with reduced in-hospital mortality due to acute stroke. However, it remains unclear whether there are improving trends in the CSC capabilities or how hospital-related factors determine quality improvement. This study examined whether CSC capabilities changed in Japan between 2010 and 2018 and and whether any changes were influenced by hospital characteristics.

Design A hospital-based cross-sectional study. Setting We sent out questionnaires to the training institutions of the Japan Neurosurgical Society and Japan Stroke Society in 2010, 2014 and 2018.

Participants 749 hospitals in 2010, 532 hospitals in 2014 and 786 hospitals in 2018 participated in the J-ASPECT study, a nationwide survey of acute stroke care capacity for proper designation of a comprehensive stroke centre in Japan.

Main outcome measures CSC capabilities were assessed using the validated scoring system (CSC score: 1-25 points) in 2010, 2014 and 2018 survey. The effect of hospital characteristics was examined using multiple logistic regression analysis.

Results Among the 323 hospitals that responded to all surveys, the implementation of 13 recommended items increased. The CSC score (median and IQR) was 16 (13-19), 18 (14-20) and 19 (15-21) for 2010, 2014 and 2018 , respectively $(p<0.001)$. There was a $\geq 20 \%$ increase in six items (eg, endovascular physicians, stroke unit and interventional coverage 24/7), and a $\leq 20 \%$ decrease in community education. A lower baseline CSC score (OR: $0.82,95 \% \mathrm{Cl} 0.75$ to 0.9 ), the number of beds $\geq 500$ (OR: $3.9,95 \% \mathrm{Cl} 1.2$ to 13.0 ) and the number of stroke physicians (7-9) (OR: 2.6, 95\% Cl 1.1 to 6.3 ) were associated with improved CSC capabilities, independent of geographical location.

Conclusions There was a significant improvement in CSC capabilities between 2010 and 2018, which was mainly related to the availability of endovascular treatment and multidisciplinary care. Our findings may be useful to determine which hospitals should be targeted to improve CSC capabilities in a defined area.

\section{Strengths and limitations of this study}

- A large-scale, representative hospitals of Japan provided data on temporal trends in the comprehensive stroke centre (CSC) capabilities for this crosssectional study.

- Hospitals actively working to improve stroke care are more likely to respond to the questionnaire, which may lead to information bias.

- The CSC score was a significant composite measure to influence in-hospital mortality of acute stroke, but little information was established on the influence of specific items.

\section{INTRODUCTION}

Stroke is the third leading cause of death and a leading cause of long-term disability in Japan. Primary and comprehensive stroke centres (CSCs) were developed to provide optimal implementation of intravenous recombinant tissue plasminogen activator (rtPA) infusion and more intensive stroke care that includes endovascular and neurosurgical treatment. ${ }^{12}$ Organised care in a stroke unit is associated with better quality of care and reduced death and dependency. ${ }^{34}$ In addition to the influence of this process, previous studies have shown that patient outcomes associated with stroke and cardiovascular diseases are influenced by the hospital case volume, ${ }^{56}$ the number of physicians, and the geographical locations of the facility. ${ }^{7}$ Progressive rural-urban disparities in acute stroke care have been reported in the USA, ${ }^{8}$ but it is not known whether such disparity exists in other countries.

In 2010, we launched the J-ASPECT study, a nationwide survey of acute stroke care capacity for proper designation of a comprehensive stroke centre in Japan. ${ }^{9} 10$ The J-ASPECT stroke database is a hospital-based, 
Japan-wide stroke registry. We demonstrated significant geographical differences in CSC capabilities in $2010,{ }^{9}$ and that CSC capabilities of a facility are associated with reduced in-hospital mortality from acute stroke. ${ }^{10}$ Thus, continuous monitoring of the CSC capabilities may be clinically meaningful to improve stroke outcomes. ${ }^{10} 11$ Since 2010, we have conducted nationwide benchmark analyses to allow participating hospitals to facilitate improvement of stroke care. However, it remains unclear whether there are improving trends in the CSC capabilities or how hospital-related factors determine quality improvement.

\section{AIMS}

We aimed to examine whether CSC capabilities in Japan changed from 2010 to 2018 and whether any recorded changes were influenced by hospital characteristics.

\section{METHODS}

\section{Institutional survey of CSC capabilities}

This cross-sectional survey used the Diagnosis Procedure Combination (DPC) discharge database from participating institutions in the J-ASPECT study. Participation in the J-ASPECT study was voluntary. Of the 1369 training institutions certified by the Japan Neurosurgical Society, the Japanese Society of Neurology and the Japan Stroke Society, 621 agreed to participate in this study. The J-ASPECT study group analysed the DPC database to gain new clinical insights on ischaemic and haemorrhagic stroke, an approach we applied again for this crosssectional survey. In this study, we sent out questionnaires to the training institutions of all three societies in 2010, 2014 and 2018 to assess CSC capabilities. The CSC capabilities of each facility were assessed with a validated scoring system (CSC score), using 25 items recommended by the Brain Attack Coalition. ${ }^{25-7}$

All items were classified into five categories: personnel, diagnostic, specific expertise, infrastructure and education. A score of 1 was assigned for meeting each item, yielding a total CSC score of up to 25. Content, constructs and predictive validity of this scoring system have been previously reported. ${ }^{12} 13$

\section{Other hospital characteristics}

Hospital characteristics, including number of beds, annual stroke hospitalisations, stroke physicians, academic status, adoption of the DPC-based payment system, ${ }^{9}$ and geographic location were obtained from the 2010 survey. The geographic location was classified according to urban employment areas (UEAs) divided into Metropolitan Employment Areas (MEAs) and Micropolitan Employment Areas (McEAs). ${ }^{9}$ The MEAs were further classified into central and outlying areas based on the commuting pattern of their inhabitants. The details of UEAs, such as total population or total land area, have been previously described. ${ }^{10}$

\section{Statistical analysis}

To explore trends in CSC capabilities, we examined implementation of the 25 items and the CSC score in the 323 consecutively participating hospitals that responded to all surveys. To examine the influence of hospital-related factors on the change in CSC capabilities, we divided the hospitals into those with or without a temporal improvement of CSC score ( $\geq 1$-point increase between 2010 and 2018). The increase of 'one point' was set based on our previous report on the CSC score. ${ }^{11}$ In that study, we showed that even a small preceding improvement of the CSC score was associated with reduced in-hospital mortality, reduced poor outcomes and higher use of acute reperfusion therapy in acute ischaemic stroke (AIS) patients; our findings also suggested the difficulty in improving the CSC score in a relatively short time period.

We used a $\chi^{2}$ test to detect differences between consecutively participating hospitals and other hospitals in the number of each hospital item. We did not perform multiple tests. Wilcoxon rank sum test was used to compare total CSC scores between consecutively participating hospitals and other hospitals.

To explore the influence of hospital-related factors on temporal improvement of CSC capabilities, multiple logistic regression models were used. To assess selection bias, we compared hospital characteristics between consecutively participating hospitals with the others. We also examined the relationship between 'number of physicians' and 'hospital size' and the relationship between 'number of physicians' and 'CSC score' using $\chi^{2}$ tests. All analyses were performed using the JMP Statistical Software V.12 (SAS Institute, Cary, North Carolina, USA). P values of $<0.05$ were considered statistically significant.

\section{Patient and public involvement}

The data for this study are based on information collected by the J-ASPECT study. Patients and the public were not involved in the development of this study.

\section{RESULTS}

Trends in the CSC capabilities from 2010 to 2018

A total of 749,532 and 786 hospitals responded to the survey in 2010, 2014 and 2018, respectively. The implementation rates of each item are shown in table 1 . The median (IQR) of the CSC scores was 14 (11-18), 17 (13-19) and 17 (12-20.3) for each year, respectively (table 1).

Among consecutively participating hospitals, there was an increase in implementation rates of the 13 items, and the CSC scores were (median and IQR): 16 (13-19), 18 (14-20) and 19 (15-21) for 2010, 2014 and 2018, respectively $(\mathrm{p}<0.001) \quad$ (table 1$)$. A marked increase $(\geq 20 \%)$ was noted in six items related to endovascular treatment (endovascular physicians and interventional coverage 24/7) and multidisciplinary care (stroke unit, specialists of emergency medicine and physical medicine/rehabilitation, and stroke rehabilitation nurses). 


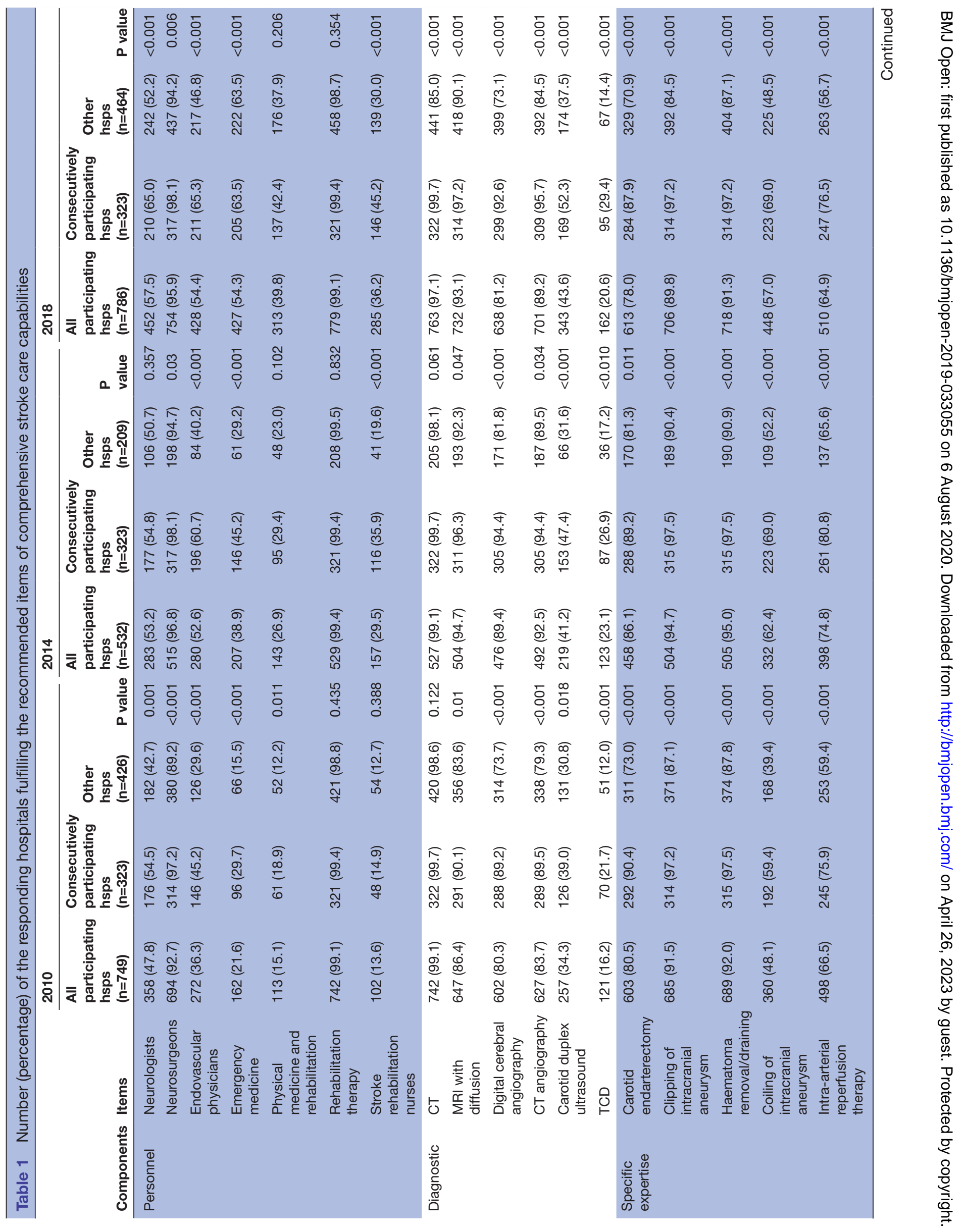




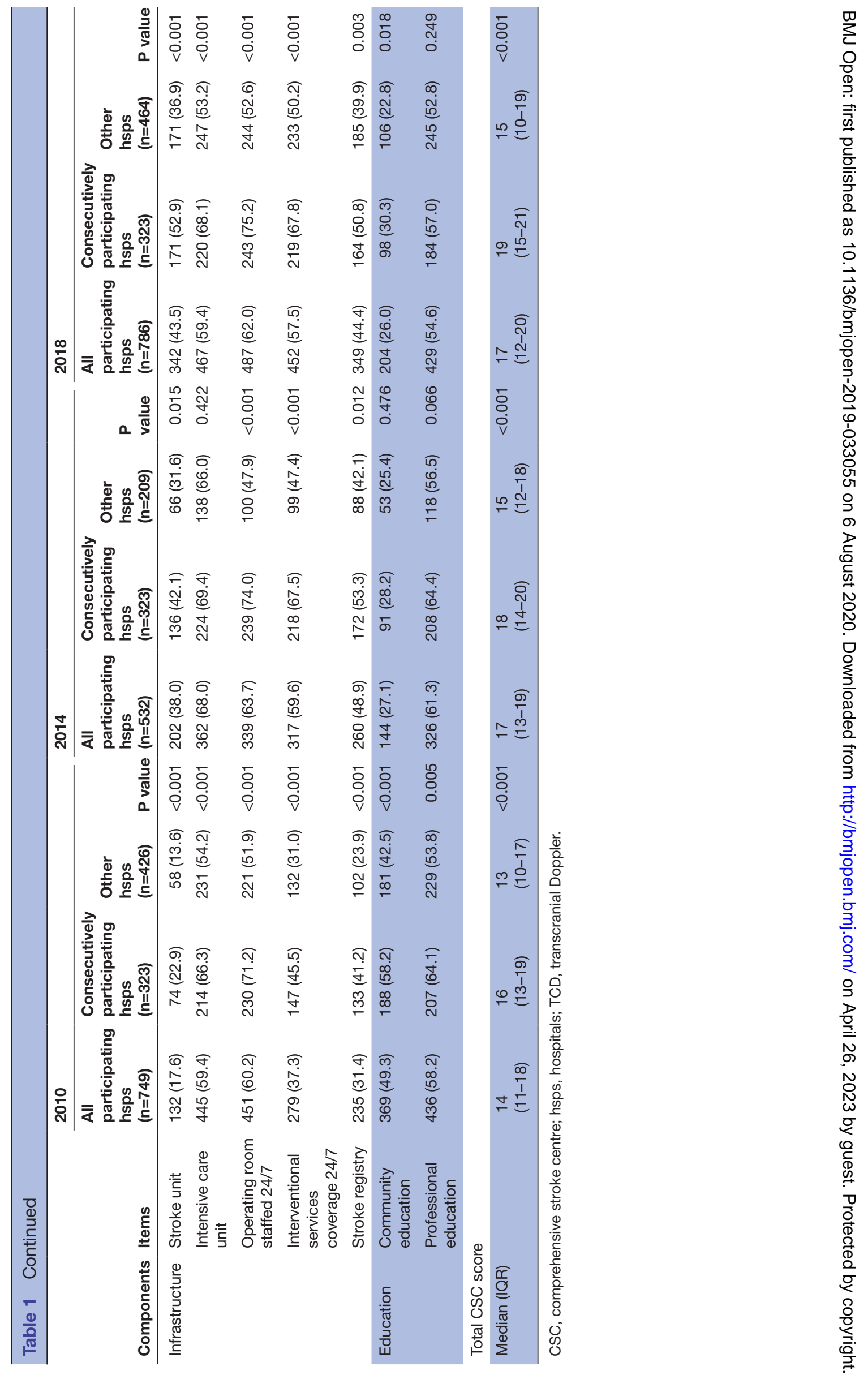


Table 2 Characteristics of comprehensive stroke care capabilities according to the geographical differences

\begin{tabular}{|c|c|c|c|c|c|c|c|c|}
\hline & \multicolumn{4}{|l|}{2010} & \multicolumn{4}{|l|}{2018} \\
\hline & $\begin{array}{l}\text { MEA central } \\
(n=186)\end{array}$ & $\begin{array}{l}\text { MEA outlying } \\
(n=79)\end{array}$ & $\begin{array}{l}\text { McEA } \\
(n=35)\end{array}$ & $P$ value & $\begin{array}{l}\text { MEA central } \\
(n=186)\end{array}$ & $\begin{array}{l}\text { MEA outlying } \\
(\mathrm{n}=79)\end{array}$ & $\begin{array}{l}\text { McEA } \\
(n=35)\end{array}$ & $P$ value \\
\hline Neurologists & $115(61.8)$ & $44(55.7)$ & $10(28.6)$ & 0.001 & $133(71.5)$ & $55(69.6)$ & $14(40.0)$ & 0.001 \\
\hline Neurosurgeons & $181(97.3)$ & 77 (97.5) & $34(97.1)$ & 0.995 & $183(98.4)$ & $78(98.7)$ & $34(97.1)$ & 0.826 \\
\hline Endovascular physicians & $101(54.3)$ & $31(39.2)$ & $8(22.9)$ & $<0.001$ & $136(73.1)$ & $49(62.0)$ & $14(40.0)$ & $<0.001$ \\
\hline $\begin{array}{l}\text { Physical medicine and } \\
\text { rehabilitation }\end{array}$ & $36(19.4)$ & $16(20.3)$ & $5(14.3)$ & 0.740 & $83(44.6)$ & $42(53.2)$ & $3(8.6)$ & $<0.001$ \\
\hline Rehabilitation therapy & $185(99.5)$ & $78(98.7)$ & 35 (100) & 0.701 & 185 (99.5) & $78(98.7)$ & $35(100)$ & 0.701 \\
\hline Stroke rehabilitation nurses & $33(17.8)$ & $9(11.4)$ & $1(2.9)$ & 0.049 & $90(48.4)$ & $41(51.9)$ & $9(25.7)$ & 0.027 \\
\hline \multicolumn{9}{|l|}{ Diagnostic } \\
\hline CT angiography & $163(87.6)$ & $72(91.1)$ & $32(91.4)$ & 0.627 & $176(94.6)$ & $77(97.5)$ & $34(97.1)$ & 0.525 \\
\hline Carotid duplex ultrasound & $71(38.1)$ & $30(38.0)$ & $14(40.0)$ & 0.977 & $95(51.1)$ & $48(60.8)$ & $15(42.9)$ & 0.164 \\
\hline TCD & $43(23.1)$ & $18(22.8)$ & $3(8.6)$ & 0.146 & $54(29.0)$ & $29(36.7)$ & $5(14.3)$ & 0.052 \\
\hline \multicolumn{9}{|l|}{ Specific expertise } \\
\hline Carotid endarterectomy & $173(93.0)$ & $68(86.1)$ & $32(91.4)$ & 0.196 & $166(89.3)$ & $71(89.9)$ & $28(80)$ & 0.260 \\
\hline $\begin{array}{l}\text { Clipping of intracranial } \\
\text { aneurysm }\end{array}$ & $183(98.4)$ & $75(94.9)$ & $34(97.1)$ & 0.280 & $181(97.3)$ & $77(97.5)$ & $34(97.1)$ & 0.995 \\
\hline Haematoma removal/draining & $183(98.4)$ & $76(96.2)$ & $34(97.1)$ & 0.546 & $182(97,9)$ & $77(97.5)$ & $35(94.3)$ & 0.485 \\
\hline Coiling of intracranial aneurysm & $119(64.0)$ & $46(58.2)$ & $13(37.1)$ & 0.012 & $143(76.9)$ & $49(62.0)$ & $17(48.6)$ & $<0.001$ \\
\hline Stroke registry & $81(43.6)$ & $31(29.1)$ & $15(42.9)$ & 0.808 & $93(50.0)$ & $47(59.5)$ & $15(42.9)$ & 0.199 \\
\hline \multicolumn{9}{|l|}{ Education } \\
\hline Community education & $110(59.1)$ & $53(67.1)$ & $17(48.6)$ & 0.164 & $55(29.6)$ & $28(35.4)$ & 8 (22.9) & 0.377 \\
\hline Professional education & $125(67.2)$ & $53(67.1)$ & $17(48.6)$ & 0.095 & $105(56.5)$ & $47(59.5)$ & $17(48.6)$ & 0.555 \\
\hline
\end{tabular}

McEA, Microplitan Employment Area; MEA, Metropolitan Employment Area; TCD, transcranial Doppler.

In addition, a moderate increase $(\leq 20 \%)$ was noted in seven items: neurologists, $24 / 7$ availability of diffusionweighted MRI, digital and CT angiography, carotid ultrasound, coiling of an intracranial aneurysm and implementation of stroke registry. In contrast, there was a marked decrease $(\leq 20 \%)$ in community education.

\section{Geographical differences in CSC capabilities between 2010 and 2018}

Among the seven items with significant geographical differences in 2010, all items in the personal component still showed a gap, despite overall improvement at all locations in 2018 (table 2). In contrast, geographical differences in all infrastructure items diminished with overall improvement and a marked improvement in the McEA in 2018.

Over the study period, geographical differences emerged in intra-arterial reperfusion therapy and the number of specialists in physical medicine/rehabilitation. The remaining item, coiling of intracranial aneurysms, showed no changes.

\section{Influence of hospital characteristics on change in CSC capabilities}

Among consecutively participating hospitals, 23 were excluded due to the missing data. Temporal improvement of CSC capabilities between 2010 and 2018 was noted in 198 hospitals (66.0\%). As for hospital characteristics, 
Table 3 Hospital characteristics those with/without temporal improvement of the CSC capabilities

\begin{tabular}{|c|c|c|c|c|}
\hline Hsp-related factors in 2010 & $\begin{array}{l}\text { All consecutively } \\
\text { participating hsps } \\
(\mathrm{n}=300)\end{array}$ & $\begin{array}{l}\text { Improvement hsps } \\
(n=198)\end{array}$ & $\begin{array}{l}\text { No improvement } \\
\text { hsps } \\
(\mathrm{n}=102)\end{array}$ & P value* \\
\hline Hsp locations & & & & 0.478 \\
\hline MEA central & $186(62.0)$ & $121(61.1)$ & $65(63.7)$ & \\
\hline MEA outlying & $79(26.3)$ & $56(28.3)$ & $23(22.6)$ & \\
\hline McEA & $35(11.7)$ & $21(10.6)$ & $14(13.7)$ & \\
\hline \multicolumn{5}{|l|}{ CSC score in 2010} \\
\hline Median (IQR) & $16(13$ to 19$)$ & 16 (13 to 18$)$ & 17 (13 to 20$)$ & 0.032 \\
\hline Academic hospital & $58(19.3)$ & $42(21.2)$ & $16(15.7)$ & 0.251 \\
\hline DPC hospital & $225(75.0)$ & $145(73.2)$ & $80(78.4)$ & 0.325 \\
\hline Number of hospital beds & & & & 0.016 \\
\hline $1-99$ & $17(5.7)$ & $9(4.6)$ & $8(7.8)$ & \\
\hline 100-299 & $68(22.7)$ & $37(18.7)$ & $31(30.4)$ & \\
\hline 300-499 & $96(32.0)$ & $62(31.1)$ & $34(33.3)$ & \\
\hline$\geq 500$ & $119(39.7)$ & $90(45.5)$ & $29(28.4)$ & \\
\hline Annual stroke case volume & & & & 0.915 \\
\hline 0-99 & $34(11.3)$ & $21(10.6)$ & $13(12.8)$ & \\
\hline $100-199$ & $73(24.3)$ & $47(23.7)$ & $26(25.5)$ & \\
\hline 200-299 & $67(22.3)$ & $45(22.7)$ & $22(21.6)$ & \\
\hline$\geq 300$ & $126(42.0)$ & $85(42.9)$ & $41(40.2)$ & \\
\hline \multicolumn{5}{|c|}{ Number of stroke physician volume } \\
\hline Median (IQR) & 6 (3 to 9) & 6 (3.8 to 9) & 5 (3 to 9.3$)$ & 0.139 \\
\hline \multicolumn{5}{|c|}{ Number of stroke physician volume quartile } \\
\hline Q1 (0-3) & 82 (27.3) & $49(24.8)$ & 33 (32.4) & \\
\hline Q2 (4-6) & $68(22.7)$ & $43(21.7)$ & $25(24.5)$ & \\
\hline Q3 (7-9) & $80(26.7)$ & $61(30.8)$ & 19 (18.6) & \\
\hline Q4 ( $\geq 10)$ & 70 (23.3) & $45(22.7)$ & $25(24.5)$ & \\
\hline \multicolumn{5}{|c|}{ Number of stroke physician volume tertile } \\
\hline T1 (0-4) & $114(38.0)$ & $72(36.4)$ & $42(41.2)$ & \\
\hline T2 (4-8) & 96 (32.0) & 63 (31.8) & $33(32.4)$ & \\
\hline T3 $(\geq 9)$ & $90(30.0)$ & 63 (31.8) & $27(26.5)$ & \\
\hline
\end{tabular}

${ }^{*} \mathrm{P}$ value: improvement versus no improvement hsps.

CSC, comprehensive stroke centre; DPC, Diagnostic Procedure Combination; Hsp, hospital; McEA, Micropolitan Employment Area; MEA,

Metropolitan Employment Area.

there were weakly significant differences in bed number $(\mathrm{p}=0.016)$ and CSC score in $2010(\mathrm{p}=0.032)$ between the two groups on univariable analysis (table 3 ).

In the logistic regression analyses, the following variables had an association with temporal improvement of CSC capabilities (table 4): a lower baseline CSC score (OR: $0.82,95 \%$ CI 0.75 to 0.9 ), bed volume $\geq 500$ (OR: $3.90,95 \%$ CI 1.17 to 13.0$)$ and moderate (7-9) number of stroke physicians (OR: 2.63, 95\% CI 1.10 to 6.27 ). In contrast, geographical location, academic status, DPCbased payment system and case volume of stroke did not show a significant association. We also performed the logistic regression analysis adjusting tertile, instead of quartile, of stroke physician volume in addition to the other adjusting factors. Except for Q3 of stroke physician volume, we found very similar results (online supplementary etable 1). Additionally, there was a significant relationship between hospital size and number of physicians $(p<0.001)$, and between CSC score and number of physicians $(\mathrm{p}<0.001)$.

\section{Selection bias}

The response rates of the 2010, 2014 and 2018 surveys were $55.0 \%, 39.7 \%$, and $49.9 \%$, respectively. We found that a selection bias did exist; in fact, the total CSC scores and most of the implementation rates of each item were significantly higher for the consecutively participating hospitals than for the others in all three surveys (table 1). 
Table 4 Multivariable analysis of the impact of hospital characteristics on one-point increases of the CSC score

\begin{tabular}{|c|c|c|c|}
\hline $\begin{array}{l}\text { Hospital-related factors } \\
\text { in } 2010\end{array}$ & OR & $95 \% \mathrm{Cl}$ & P value \\
\hline \multicolumn{4}{|l|}{ Hospital locations } \\
\hline MEA central & Ref. & & \\
\hline MEA outlying & 1.42 & 0.76 to 2.65 & 0.269 \\
\hline McEA & 0.82 & 0.36 to 1.86 & 0.632 \\
\hline CSC score in 2010 & 0.82 & 0.75 to 0.90 & $<0.001$ \\
\hline Academic hospital & 1.37 & 0.54 to 3.48 & 0.506 \\
\hline DPC hospital & 0.77 & 0.41 to 1.42 & 0.397 \\
\hline \multicolumn{4}{|l|}{ Number of beds } \\
\hline $1-99$ & ref. & & \\
\hline 100-299 & 1.16 & 0.37 to 3.66 & 0.794 \\
\hline $300-499$ & 1.68 & 0.56 to 5.10 & 0.358 \\
\hline$\geq 500$ & 3.9 & 1.17 to 13.00 & 0.027 \\
\hline \multicolumn{4}{|l|}{ Annual stroke case volume } \\
\hline $1-99$ & ref. & & \\
\hline $100-199$ & 1.62 & 0.64 to 4.07 & 0.305 \\
\hline 200-299 & 2.41 & 0.89 to 6.49 & 0.083 \\
\hline$\geq 300$ & 2.74 & 0.99 to 7.54 & 0.051 \\
\hline
\end{tabular}

Number of stroke physician volume quartile

\begin{tabular}{llll} 
Q1 (0-3) & Ref. & & \\
Q2 (4-6) & 1.77 & 0.81 to 3.88 & 0.153 \\
Q3 (7-9) & 2.63 & 1.10 to 6.27 & 0.030 \\
Q4 $(\geq 10)$ & 1.58 & 0.57 to 4.38 & 0.380 \\
\hline
\end{tabular}

${ }^{*} \mathrm{P}$ value: improvement versus no improvement hospitals. CSC, comprehensive stroke centre; DPC, Diagnostic Procedure Combination; McEA, Micropolitan Employment Area; MEA, Metropolitan Employment Area.

Consecutively participating hospitals were more likely to be MEA central, be academic, have a larger number of hospital beds, have a higher annual stroke admission rate and have more stroke physicians (online supplementary etable 2).

\section{DISCUSSION}

We found an overall improvement in CSC capabilities between 2010 and 2018 and and different trends in geographical disparities for different items. Hospitals with a higher number of hospital beds, an intermediate number of stroke physicians and a lower baseline CSC score had a higher likelihood of improving their CSC capabilities.

\section{Temporal changes to CSC capabilities}

In addition to a significant increase in CSC capabilities, there was a marked increase in implementation of the items, mainly related to endovascular treatment and multidisciplinary care. Of note, we previously showed that interventional $24 / 7$ coverage and the presence of physical medicine/rehabilitation specialists were associated with reduced in-hospital mortality for patients with subarachnoid haemorrhage, whereas availability of neurologists and stroke units were associated with reduced in-hospital mortality and better functional outcomes, respectively, for those with ischaemic stroke. ${ }^{13}$

These findings are consistent with those of prior studies, which have shown that admission to a stroke unit with organised stroke care is associated with better quality of care and outcomes in those who experience an acute stroke. ${ }^{314}$ Although the use of mechanical thrombectomy for large vessel AIS has been rapidly increasing, only $3.3 \%$ of $15.1 \%$ potentially eligible AIS patients received it in 2016. ${ }^{15}$ Improvement of CSC capabilities, especially related to endovascular treatment and multidisciplinary care, should contribute to improved quality of care and outcomes in patients with acute stroke.

The decreased implementation of community education observed in this study may be explained by the limited number of stroke physicians available for this purpose due to an increased burden of stroke care (eg, emergent endovascular calls). ${ }^{16}$ Stroke educational campaigns have the potential to improve knowledge and awareness, but public campaigns are usually expensive and short lived, and may not achieve any significant improvement. ${ }^{17}$

\section{Diminished and emerging geographical disparities}

Determining rural/urban differences in CSC capabilities may support the development of targeted interventions to improve stroke care and outcomes in rural areas. We found differing trends in implementation of the items according to personnel and infrastructure components. Rural areas are associated with reduced access to optimal stroke care and a lower use of acute stroke intervention. ${ }^{18}$ The diminished disparities in implementation of stroke units in this study might result in a higher use of rt-PA infusion in rural areas. ${ }^{19}$

The emerging disparities in implementation of intraarterial reperfusion therapy deserve some attention. Since the evidence regarding the efficacy of acute endovascular reperfusion therapy was established in $2015,{ }^{20}$ relocation of relevant specialists might have occurred from rural to urban areas to meet the urgent need created by more widespread use. In addition, a high prevalence of neurointerventional physician burnout may require centralisation of acute endovascular reperfusion treatment. ${ }^{21}$

\section{Influence of hospital-related factors on improvement of CSC capabilities}

Our study showed the impact of specific hospital-related factors on improvement of CSC capabilities, which may be useful to determine which hospitals should be targeted to improve CSC capabilities, and in what regions. In rural areas, where medical resources are limited, centralisation of acute stroke care in large hospitals may be needed. We also found a significant relationship between CSC score and number of physicians. This means that, in 2010, institutions with more physicians tended to have higher 
baseline CSC scores. The reason that a physician volume of more than 10 did not affect the improvement of the CSC score may be explained by the ceiling effect of a high baseline CSC score in 2010.

\section{Limitations}

There are several limitations of this study. First, since the total CSC scores and most of the implementation rates of each item were significantly higher for the consecutively participating hospitals than for the others in all three surveys, our findings may have included biased information. Second, the CSC score was a significant composite measure to influence in-hospital mortality of acute stroke, but little information was established on the influence of specific items. Third, we did not determine the influence of unmeasured confounders. Fourth, the CSC score is a self-reported questionnaire rather than the result of any formal certification process. In Japan, the official certification process for primary stroke centres just began in 2019. The criteria for CSC certification is now under discussion by the Japan Stroke Society. The results of this study could have a significant impact on the recommended items and criteria for the designation of official CSCs in Japan. After the official certification process for CSCs is implemented, we plan to reassess the effect of CSC capabilities on AIS patients. Finally, the 2014 data did not factor into this analysis because of the small number of participants in that year. Further research is required to examine the effect of 2014 data on the analysis.

\section{CONCLUSIONS}

The CSC capabilities in Japan improved between 2010 and 2018, especially related to endovascular treatment and multidisciplinary care. Our findings may be useful to determine which hospitals should be targeted to improve CSC capabilities in a defined area.

\section{Author affiliations}

${ }^{1}$ Department of Neurosurgery, Graduate School of Medical Sciences, Kyushu University, Fukuoka, Japan

${ }^{2}$ Department of Cerebrovascular Medicine, National Cerebral and Cardiovascular Center, Suita, Japan

${ }^{3}$ Department of Clinical Trials and Research, National Hospital Organization Nagoya Medical Center, Nagoya, Japan

${ }^{4}$ Department of Health Communication, Graduate School of Medical Sciences, Kyushu University, Fukuoka, Japan

${ }^{5}$ Department of Neurosurgery, School of Medicine, Iwate Medical University, Morioka, Japan

${ }^{6}$ Department of Neurosurgery, Kyorin University Hospital, Mitaka, Tokyo, Japan ${ }^{7}$ Department of Medicine and Clinical Science, Kyusyu University Graduate School of Medicine, Fukuoka, Japan

Acknowledgements We thank the Japan Neurosurgical Society and the Japan Stroke Society for their collaboration. We also thank all participating hospitals in the J-ASPECT study for contributing to this project. The institutions and names of the J-ASPECT Study Collaborators are listed in Supplemental Appendix 1.

Contributors AKurogi and KI drafted the manuscript. AN, KN, AKada, DO, AH and $\mathrm{KI}$ were involved in study concept, design and obtaining funding. AKada, DO, AH, $\mathrm{KO}, \mathrm{YS}, \mathrm{TK}, \mathrm{KA}$ and $\mathrm{KI}$ were involved in the analysis of data. KO, YS, TK and KI were involved in the acquisition of data. All authors reviewed the study report, made comments or suggestions on the manuscript drafts, and approved the final version.
Funding The J-ASPECT study is supported by the Practical Research Project for lifestyle-related diseases, including cardiovascular diseases and diabetes mellitus, managed by the Japan Agency for Medical Research and Development (JP19ek0210088 and JP19ek0210129); Grants-in-Aid from the Japanese Ministry of Health, Labour, and Welfare; and KAKENHI grants (18H02914) from the Japan Society for the Promotion of Science.

Patient and public involvement Patients and/or the public were not involved in the design, or conduct, or reporting, or dissemination plans of this research.

Patient consent for publication Not required.

Ethics approval The study was approved by the Kyushu University's institutional review board, which waived the requirement for individual informed consent (№. 28-335).

Provenance and peer review Not commissioned; externally peer reviewed.

Data availability statement No data are available. The individual patient data are not publicly available because of the memorandum signed by the director of the participating hospitals and the principal investigator of the J-ASPECT Study group.Department of Neurosurgery, Graduate School of Medical Sciences, Kyushu University, Fukuoka, Japan. Email: kiihara@ns.med.kyushu-u.ac.jp.

Open access This is an open access article distributed in accordance with the Creative Commons Attribution Non Commercial (CC BY-NC 4.0) license, which permits others to distribute, remix, adapt, build upon this work non-commercially, and license their derivative works on different terms, provided the original work is properly cited, appropriate credit is given, any changes made indicated, and the use is non-commercial. See: http://creativecommons.org/licenses/by-nc/4.0/.

\section{ORCID iDs}

Ai Kurogi http://orcid.org/0000-0002-2740-0990

Daisuke Onozuka http://orcid.org/0000-0001-9596-9188

\section{REFERENCES}

1 Alberts MJ, Hademenos G, Latchaw RE, et al. Recommendations for the establishment of primary stroke centers brain attack coalition. JAMA 2000;283:3102-9.

2 Alberts MJ, Latchaw RE, Selman WR, et al. Recommendations for comprehensive stroke centers: a consensus statement from the brain attack coalition. Stroke 2005;36:1597-616.

3 Stroke Unit Trialists' Collaboration. Organised inpatient (stroke unit) care for stroke. Cochrane Database Syst Rev 2013;9:CD000197.

4 Bray BD, Ayis S, Campbell J, et al. Associations between the organisation of stroke services, process of care, and mortality in England: prospective cohort study. BMJ 2013;346:f2827.

5 Hall RE, Fang J, Hodwitz K, et al. Does the volume of ischemic stroke admissions relate to clinical outcomes in the Ontario stroke system? Circ Cardiovasc Qual Outcomes 2015;8:S141-7.

6 Ross JS, Normand S-LT, Wang Y, et al. Hospital volume and 30day mortality for three common medical conditions. N Engl J Med 2010;362:1110-8.

7 Howard G, Kleindorfer DO, Cushman M, et al. Contributors to the excess stroke mortality in rural areas in the United States. Stroke 2017;48:1773-8.

8 Gonzales S, Mullen MT, Skolarus L, et al. Progressive rural-urban disparity in acute stroke care. Neurology 2017;88:441-8.

9 lihara K, Nishimura K, Kada A, et al. The impact of comprehensive stroke care capacity on the hospital volume of stroke interventions: a nationwide study in Japan: J-ASPECT study. J Stroke Cerebrovasc Dis 2014;23:1001-18.

10 UEA urban employment area. Metropolitan employement area data. Available: http://www.csis.u-tokyo.ac.jp/UEA/uea_data_e.htm [Accessed 13 Jan 2020].

11 Kada A, Ogasawara K, Kitazono T, et al. National trends in outcomes of ischemic stroke and prognostic influence of stroke center capability in Japan, 2010-2016. Int J Stroke 2019;26:174749301988452.

12 lihara K, Nishimura K, Kada A, et al. Effects of comprehensive stroke care capabilities on in-hospital mortality of patients with ischemic and hemorrhagic stroke: J-ASPECT study. PLOS One 2014;9:e96819.

13 Kada A, Nishimura K, Nakagawara J, et al. Development and validation of a score for evaluating comprehensive stroke care capabilities: J-ASPECT study. BMC Neurol 2017;17:46. 
14 Svendsen ML, Ehlers LH, Ingeman A, et al. Higher stroke unit volume associated with improved quality of early stroke care and reduced length of stay. Stroke 2012;43:3041-5.

15 Smith EE, Saver JL, Cox M, et al. Increase in endovascular therapy in get with the Guidelines-Stroke after the publication of pivotal trials. Circulation 2017;136:1-10.

16 Williams MM, Wilson TA, Leslie-Mazwi T, et al. The burden of neurothrombectomy call: a multicenter prospective study. $J$ Neurointerv Surg 2018;10:1143-8.

17 Rasura M, Baldereschi M, Di Carlo A, et al. Effectiveness of public stroke educational interventions: a review. Eur J Neurol 2014;21:11-20.

18 Kapral MK, Austin PC, Jeyakumar G, et al. Rural-Urban differences in stroke risk factors, incidence, and mortality in people with and without prior stroke. Circ Cardiovasc Qual Outcomes 2019;12:e004973.

19 Domino JS, Baek J, Meurer WJ, et al. Emerging temporal trends in tissue plasminogen activator use: results from the basic project. Neurology 2016;87:2184-91.

20 Goyal M, Menon BK, van Zwam WH, et al. Endovascular thrombectomy after large-vessel ischaemic stroke: a meta-analysis of individual patient data from five randomised trials. Lancet 2016;387:1723-31.

21 Fargen KM, Arthur AS, Leslie-Mazwi T, et al. A survey of burnout and professional satisfaction among United States neurointerventionalists. J Neurointerv Surg 2019;11:1100-4. 